\title{
Congenital Hypothyroidism and Bone Remodeling Cycle
}

\author{
Nazmi Mutlu Karakaş ${ }^{1}$, Sibel Tulgar Kınık², Beril Özdemir ${ }^{1}$, Nursel Muratoğlu Şahin ${ }^{3}$, M. Ağah Tekindal ${ }^{4}$, Ayşegül Haberal $^{5}$ \\ ${ }^{1}$ Başkent University Faculty of Medicine, Department of Pediatrics, Ankara, Turkey \\ ${ }^{2}$ Başkent University Faculty of Medicine, Department of Pediatric Endocrinology, Ankara, Turkey \\ ${ }^{3}$ Dr. Sami Ulus Obstetrics and Gynecology, Children's Health and Disease Training and Research Hospital, Clinic of Pediatric Endocrinology, \\ Ankara, Turkey \\ ${ }^{4}$ izmir University Faculty of Medicine, Department of Biostatistics, Izmir, Turkey \\ ${ }^{5}$ Başkent University Faculty of Medicine, Department of Biochemistry, Ankara, Turkey
}

\section{What is already known on this topic?}

Long-term treatment with LT4 increases bone resorption in patients with congenital hypothyroidism.

\section{What this study adds?}

Our results suggest that with effective vitamin D and thyroxin replacement, congenital hypothyroidism is not a deleterious factor for bone turnover.

\section{Abstract}

Objective: The present study aimed to evaluate the biochemical markers of bone turnover in children with congenital hypothyroidism during the course of treatment as compared to healthy children selected as controls.

Methods: The study included 31 children with congenital hypothyroidism and 29 healthy children. In both groups, we evaluated serum procollagen type-1 N-terminal propeptide (PINP) and tartrate-resistant acid phosphatase type 5b isoform (TRACP 5b) levels as bone turnover markers.

Results: In both groups, thyroid hormone levels were within normal limits. The levels of vitamin D were significantly higher in the cases with congenital hypothyroidism. Although PINP levels were not found to be different, TRACP 5b levels which are related to osteoclastic activities were significantly higher in the control group.

Conclusion: We did not detect an increase in bone resorption in patients with congenital hypothyroidism, despite long-term treatment with LT4. Our results suggest that with effective vitamin D treatment and thyroxin replacement, congenital hypothyroidism is not a deleterious factor for bone turnover.

Keywords: Congenital hypothyroidism, bone marker, thyroxin

\section{Introduction}

Congenital hypothyroidism $(\mathrm{CH})$ is one of the most common preventable causes of intellectual disability (1). Effects of hypothyroidism have decreased in babies administered treatment in accordance with the neonatal screening program (2). Untreated $\mathrm{CH}$ results in delayed bone age, growth retardation, and short stature (3).
Thyroid hormones also have important effects on the bone remodeling cycle. However, this effect has been shown to increase in favor of bone resorption, especially in thyrotoxicosis (4). In some studies in adults, longterm treatment with levothyroxine has been reported to decrease bone density, which may result in bone fractures $(4,5,6)$. In contrast, some studies have indicated that long-term treatment would not affect bone density $(7,8)$. 
Both hypothyroidism and hyperthyroidism have been associated with an increased risk of fractures. It has been determined that remodeling increases in adults in the course of hypothyroidism; in this situation, osteoclastic duration is increased twofold, whereas osteoblastic duration is prolonged fourfold. These changes result in low bone turnover and an overall failure to gain bone mass and mineral (3).

In children diagnosed with $\mathrm{CH}$ in the neonatal period and treated for a long time, the bone remodeling cycle may indicate the effects of thyroid hormone treatment or those of $\mathrm{CH}$. Additionally, the presence of vitamin $\mathrm{D}$ deficiency also affects the bone cycle (9). In the assessment of the bone cycle by serum analysis, the new bone formation may be evaluated by the level of serum procollagen type 1 $\mathrm{N}$-terminal propeptide (PINP), and bone resorption by the level of the enzyme tartrate-resistant acid phosphatase type $5 \mathrm{~b}$ isoform (TRACP $5 \mathrm{~b}$ ), which is secreted by osteoclasts (10). The present study aimed to evaluate the biochemical markers of bone turnover in children with $\mathrm{CH}$ who had been followed up during the course of treatment and in healthy children selected as controls.

\section{Methods}

The study included 31 children with $\mathrm{CH}$ followed up by the Başkent University, School of Medicine, Pediatric Endocrinology outpatient clinic and 29 healthy children followed up by the General Pediatrics outpatient clinic. All patients and their families were informed about the study, and consent was obtained from the families. Blood samples were withdrawn during the blood sampling for medical purposes.

Of the 31 patients with $\mathrm{CH}, 14$ were cases of hypoplastic thyroid gland, one had agenesis, one had an ectopic thyroid gland, 14 had thyroid dyshormonogenesis, and one had a fetal goiter related to the TPO gene mutation. The initial LT4 treatment was administered at a dose of $7.5-15 \mu \mathrm{g} / \mathrm{kg} / \mathrm{day}$ during the neonatal period.

The cases in the control group $(n=29)$ were selected from those who had been followed up by the General Pediatrics outpatient clinic and had no chronic disease or abnormal neonatal screening result. They were not taking any medication. We did not question the dosage and duration of vitamin D intake in the two groups.

Chronological age, weight, height, and percent of ideal weight for height were evaluated in all patients. All blood samples were withdrawn in the morning, at the same time. The serum levels of calcium, phosphorus, alkaline phosphatase (ALP), magnesium, thyroid-stimulating hormone (TSH), free thyroxine $\left(\mathrm{fT}_{4}\right)$, parathyroid hormone (PTH), 25 hydroxycholecalciferol [25(OH) $\mathrm{D}_{3}$-Vitamin D], PINP, TRACP $5 \mathrm{~b}$, and urine calcium/creatinine ratio were analyzed in the biochemistry laboratory of Başkent University.

$\mathrm{CH}$ and control groups were compared according to vitamin D status, deficient or non-deficient.

Venous blood samples were drawn and sera were stored at $-20{ }^{\circ} \mathrm{C}$ after centrifugation until testing. All assays were carried out at the same time. The levels of $25(\mathrm{OH})$ D were assayed using chemiluminescent microparticle immunoassay (Abbott Architect I2000 analyzer). The architect 25(OH)D assay is designed to have a limit of detection (LoD) of $\leq 10.0 \mathrm{ng} / \mathrm{mL}$. Serum levels of calcium, phosphorus, ALP, magnesium, TSH, and $\mathrm{fT}_{4}$ were measured in the blood cell counter using an Abbott Cell-Dyn Ruby System (Abbott Diagnostic, Santa Clara, CA, USA).

Vitamin D levels at or below $15 \mathrm{ng} / \mathrm{mL}$ were defined as vitamin D deficiency (9).

PINP was measured by kit which is a sandwich enzyme immunoassay for in vitro quantitative measurement of PINP in human serum incubated for 30 minutes at $37{ }^{\circ} \mathrm{C}$ after covering it with the Plate sealer. The minimum detectable dose of PINP is typically less than $6.2 \mathrm{pg} / \mathrm{mL}$. The intra- and inter-assay coefficients of variation $(\mathrm{CV})$ reported by the manufacturer are $<10 \%$ and $<12 \%$ (Uscn Life Science Inc. Wuhan, Hubei, PRC).

TRACP was assayed by an immunoCapture Enzyme-Activity Assay in serum (BioVendor Research and Diagnostic Products, Czech Republic). In the BioVendor Human TRAP 5 Assay, calibrators, quality control and samples are incubated in microplate wells pre-coated with monoclonal anti-human TRAP 5 antibody. After a thorough wash, TRACP $5 \mathrm{~b}$ bound to the antibody is allowed to react with the pNPP substrate at $\mathrm{pH}$ 5.5. The reaction is stopped by addition of hydroxine solution and absorbance of the resulting yellow color product is measured. The absorbance is proportional to the enzymatic activity of TRACP 5b. A calibration curve is constructed by plotting absorbance values against enzyme activities of recombinant TRACP 5 calibrators, and enzyme activity of unknown samples are determined (U/I) using this calibration curve. LoD is calculated from the real TRAP 5 values in wells and is $0.01 \mathrm{U} / \mathrm{I}$. The intra- and inter-assay CVs reported by manufacturer are $2.4 \%$ and $7.6 \%$.

This study was approved by the Başkent University Institutional Review Board and Ethics Committee (Project No: KA12/46) and supported by the Başkent University Research Fund. 


\section{Statistical Analysis}

Data were analyzed using the SPSS 20 (IBM Corp. Released 2011. IBM SPSS Statistics for Windows, Version 20.0. Armonk, NY: IBM Corp.) statistical software. Values were expressed as mean \pm standard deviation, median (maximum-minimum), percentage, and frequency. Variables were evaluated after controlling the normality and homogeneity of variance prerequisites (Shapiro-Wilk and Levene's tests). Data were compared between the two groups using the independent t-test (Student's t-test); the Mann-Whitney U-test was used in the absence of prerequisites. Categorical data were analyzed using the Fisher's exact test and chi-square test. When the expected frequencies were lower than $20 \%$, evaluation by the "Monte Carlo simulation method" was performed in order to include these frequencies in the analysis. A p-value $<0.05$ was accepted as statistically significant.

\section{Results}

The characteristics of the cases with $\mathrm{CH}$ and control subjects are presented in Table 1 . The values of chronological age, height-for-age, body weight, height, and percent of ideal weight for height were not different in the $\mathrm{CH}$ and control groups. Laboratory results on serum calcium, phosphorus, magnesium, ALP, $\mathrm{fT}_{4}, \mathrm{TSH}, \mathrm{PTH}$, and PINP levels were also not statistically different from one another and were also in the normal range. Mean TRACP $5 b$ levels were significantly higher in the control group. The levels of vitamin D were significantly higher in the cases with $\mathrm{CH}$ (Table 1).

According to vitamin D status, TRACP $5 \mathrm{~b}$ levels were significantly higher in controls. PINP levels were not found to be different (Table 2).

\section{Discussion}

The acid phosphatases are lysosomal enzymes, and the isoform $5 \mathrm{~b}$ secreted from the osteoclasts is a marker used to detect bone resorption. On the other hand, procollagen type $1 \mathrm{~N}$-terminal propeptide is a marker used for the evaluation of bone formation (11). In the present study, bone turnover was evaluated in children with and without $\mathrm{CH}$.

Bone is a metabolically active tissue that undergoes continuous remodeling throughout life. In the course of bone remodeling, bone resorption is closely associated with new bone formation. Bone resorption and formation can be affected by some diseases and this process may be evaluated by the serum levels of several markers (10). The effect of congenital non-goiter hypothyroidism on bone is still not completely understood (12). Population studies have demonstrated that both hypothyroidism and hyperthyroidism affect bone remodeling and that they may increase the risk of bone fractures. Studies conducted on mice have shown that TSH affects the bone remodeling cycle

Table 1 . The characteristics of the cases with congenital hypothyroidism and the controls

\begin{tabular}{|c|c|c|c|c|c|}
\hline & $\mathrm{n}$ & $\begin{array}{l}\text { Congenital } \\
\text { hypothyroidism }\end{array}$ & $\mathrm{n}$ & Controls & $\mathrm{p}$-values \\
\hline Male/Female & 31 & $21 / 11$ & 28 & $17 / 11$ & 0.091 \\
\hline Body weight (kilograms) & 31 & $17.56 \pm 6.45$ & 28 & $16.36 \pm 3.06$ & 0.373 \\
\hline Height (cm) & 31 & $101.65 \pm 10.55$ & 28 & $104.96 \pm 12.47$ & 0.399 \\
\hline Phosphorus (mg/dL) & 31 & $5.12 \pm 0.35$ & 28 & $4.71 \pm 0.54$ & 0.082 \\
\hline Alkaline phosphatase (U/L) & 31 & $196.38 \pm 43.06$ & 28 & $238.11 \pm 28.75$ & 0.442 \\
\hline 25-OH-Vit D (ng/mL) & 29 & $29.22 \pm 10.54$ & 28 & $20.87 \pm 7.02$ & $0.001^{*}$ \\
\hline PINP $\quad(p g / m L)$ & 31 & $16.82 \pm 2.21$ & 28 & $17.83 \pm 7.90$ & 0.499 \\
\hline PTH (pg/mL) & 27 & $35.11 \pm 2.98$ & 21 & $23.13 \pm 4.38$ & 0.024 \\
\hline Magnesium (mg/dL) & 22 & $2.09 \pm 0.12$ & 28 & $2.07 \pm 0.13$ & 0.957 \\
\hline Urine $\mathrm{Ca} / \mathrm{Cre}$ & 20 & $0.14 \pm 0.04$ & 18 & $0.14 \pm 0.03$ & 0.934 \\
\hline
\end{tabular}

TRACP 5b: tartrate-resistant acid phosphatase type 5b, PINP: procollagen type-1 $\mathrm{N}$-terminal propeptide, PTH: parathyroid hormone, $\mathrm{fT}_{4}$ : free thyroxine,

TSH: thyroid-stimulating hormone, Ca/Cre: calcium/creatinine ratio, 25-OH-Vit D: 25 hydroxycholecalciferol Vitamin D 
Table 2. Comparison of the two groups according to vitamin $\mathrm{D}$ status

\begin{tabular}{|c|c|c|c|c|c|c|c|c|c|c|}
\hline & \multicolumn{4}{|c|}{ Vitamin D levels: 0 to $14.99 \mathrm{ng} / \mathrm{mL}$} & \multicolumn{6}{|c|}{ Vitamin D levels: $\geq 15 \mathrm{ng} / \mathrm{mL}$} \\
\hline & $=$ & 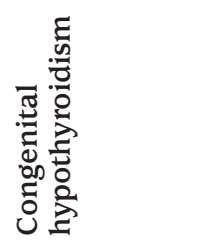 & $=$ & \begin{tabular}{l}
$\frac{n}{0}$ \\
\multirow{2}{0}{} \\
0 \\
0
\end{tabular} & $\begin{array}{l}\frac{0}{2} \\
\frac{1}{3} \\
\text { d. }\end{array}$ & $\approx$ & 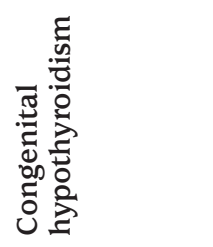 & $=$ & $\begin{array}{l}\frac{n}{0} \\
\stackrel{0}{0} \\
0 \\
0\end{array}$ & $\begin{array}{l}\frac{0}{2} \\
\frac{1}{3} \\
\text { d }\end{array}$ \\
\hline Height (cm) & 2 & $110.5 \pm 7.07$ & 5 & $108.4 \pm 8.2$ & 0.766 & 27 & $101.13 \pm 17.7$ & 23 & $104.2 \pm 13.2$ & 0.497 \\
\hline Body weight (kg) & 2 & $18.95 \pm 0.49$ & 5 & $16.88 \pm 2.72$ & 0.357 & 27 & $17.5 \pm 6.8$ & 23 & $16.2 \pm 3.1$ & 0.402 \\
\hline $\begin{array}{l}\text { Percent of ideal } \\
\text { weight for height }\end{array}$ & 2 & $102.7 \pm 8.8$ & 5 & $99.5 \pm 7.37$ & 0.641 & 27 & $101.6 \pm 10.7$ & 23 & $95.9 \pm 11.5$ & 0.057 \\
\hline Calcium (mg/dL) & 2 & $9.65 \pm 0.78$ & 5 & $9.56 \pm 0.19$ & 0.793 & 27 & $9.91 \pm 0.39$ & 23 & $9.75 \pm 0.31$ & 0.109 \\
\hline PINP (pg/mL) & 2 & $18.25 \pm 1.12$ & 5 & $27.1 \pm 7.34$ & 0.503 & 27 & $16.73 \pm 2.33$ & 23 & $15.8 \pm 1.94$ & 0.136 \\
\hline TRACP $5 b(\mathrm{U} / \mathrm{L})$ & 2 & $0.63 \pm 0.09$ & 5 & $9.98 \pm 1.21$ & 0.001 * & 27 & $1.78 \pm 0.58$ & 23 & $8.5 \pm 2.17$ & $0.001 *$ \\
\hline TSH $(\mu \mathrm{IU} / \mathrm{mL})$ & 2 & $2.35 \pm 4.45$ & 5 & $1.38 \pm 0.22$ & 0.073 & 27 & $2.12 \pm 2.5$ & 22 & $1.88 \pm 0.99$ & 0.081 \\
\hline $\mathrm{fT}_{4}(\mathrm{ng} / \mathrm{dL})$ & 2 & $1.35 \pm 0.07$ & 5 & $1.25 \pm 0.13$ & 0.356 & 27 & $1.21 \pm 1.19$ & 22 & $1.16 \pm 0.14$ & 0.09 \\
\hline PTH (pg/mL) & 2 & $49.25 \pm 24.35$ & 4 & $31.3 \pm 10.01$ & 0.062 & 24 & $34.57 \pm 13.81$ & 17 & $26.79 \pm 4.60$ & 0.145 \\
\hline $\begin{array}{l}\text { Magnesium } \\
(\mathrm{mg} / \mathrm{dL})\end{array}$ & 2 & $2.02 \pm 0.02$ & 5 & $1.95 \pm 0.13$ & 0.867 & 20 & $2.10 \pm 0.12$ & 23 & $2.08 \pm 0.01$ & 0.923 \\
\hline Urine $\mathrm{Ca} / \mathrm{cre}$ & 1 & 0.31 & 4 & $0.12 \pm 0.05$ & - & 18 & $0.138 \pm 0.039$ & 14 & $0.146 \pm 0.039$ & 0.887 \\
\hline
\end{tabular}

ALP: alkaline phosphatase, TRACP 5b: tartrate-resistant acid phosphatase type 5b, PINP: procollagen type-1 N-terminal propeptide, PTH: parathyroid hormone, $\mathrm{fT}_{4}$ : free thyroxine, TSH: thyroid-stimulating hormone, $\mathrm{Ca} / \mathrm{Cre}$ : calcium/creatinine ratio

negatively $(4,5,6,7,8)$. Papadimitriou et al (13) determined that the low levels of TSH do not lead to bone loss in mice. In our study, $\mathrm{TSH}$ and $\mathrm{fT}_{4}$ levels were found to be similar in the hypothyroid and control groups, but the level of TRACP $5 \mathrm{~b}$, which is an indicator of bone resorption, was found to be lower in the hypothyroid group; in other words, bone resorption was low in hypothyroid cases.

Engler et al (14) showed that the thyroid hormones also affect bone turnover. In this study, the values indicating bone resorption were high in the cases with hyperthyroidism, before the administration of anti-thyroid treatment.

In several studies conducted on adults, TSH was reported to be suppressed by the administration of LT4 in patients with thyroid cancer and non-toxic goiter who did not have thyrotoxicosis, and bone density was reported to be decreased $(4,5,6)$. In contrast to these results, Franklyn et al (7) and Marcocci et al (8) did not detect any change in bone density following treatment with LT4 for as long as 8 to 10 years. Leger et al (4) did not detect a change in bone mineral density in favor of bone resorption, in patients undergoing long-term LT4 treatment. Similarly, in our study, any effect on bone resorption has not been demonstrated in the group with $\mathrm{CH}$.
Vitamin D contributes to bone turnover, and it is used as a supportive treatment, starting in infancy. We determined the level of vitamin $\mathrm{D}$ to be significantly higher in children with $\mathrm{CH}$. When the cases were subdivided according to their vitamin D levels, TRACP $5 \mathrm{~b}$ levels were found to be higher in the controls in both vitamin D sufficiency and deficiency situations. The value of PINP, which indicates the formation of new bone, did not differ significantly between the groups. In this study, we did not detect an increase in bone resorption in patients followed up in our clinic. The children with $\mathrm{CH}$ might have received more effective vitamin $\mathrm{D}$ replacement due to their close and more frequent follow-ups. The mean duration of follow-up in our hypothyroid patients was four years which may be considered as one of the limitations of the study. We did not question the duration and dose of vitamin $\mathrm{D}$ intake in the $\mathrm{CH}$ and control groups which is the other limitation.

Reference values for TRACP $5 \mathrm{~b}$ have been published for Chinese in 2005 and subsequently for Caucasian children, in 2007 and $2012(15,16,17)$. Rauchenzauner et al (16) has reported the TRACP $5 \mathrm{~b}$ values for $50^{\text {th }}$ percentile as $8.1 \mathrm{U} / \mathrm{L}$ for boys and 6.8 for girls in the $0-18$ age group. Fischer et al 
(17) determined the TRACP $5 \mathrm{~b}$ values for $50^{\text {th }}$ percentile at age 4 years to be $13.8 \mathrm{U} / \mathrm{L}$ for boys and $17 \mathrm{U} / \mathrm{L}$ for girls (17). The distribution of normal TRACP levels showed a wide range, depending on age, sex, and pubertal stage. Vitamin $\mathrm{D}$ levels were not given in the above studies.

Our study included an age-matched healthy prepubertal control group. We measured the vitamin D levels in both groups. We speculate that the main reason for the higher TRACP $5 b$ levels in the controls might be the lower vitamin D levels.

In conclusion, we did not detect an increase in bone resorption in patients with $\mathrm{CH}$, despite long-term treatment with LT4. Our results suggest that with effective vitamin D and thyroxin replacement, $\mathrm{CH}$ is not a deleterious factor for bone turnover.

\section{Ethics}

Ethics Committee Approval: This study was approved by the Başkent University Institutional Review Board and Ethics Committee (Project No: KA12/46).

Informed Consent: All patients and their families were informed about the study, and consent was obtained from the families.

Peer-review: Externally peer-reviewed.

\section{Authorship Contributions}

Concept: Sibel Tulgar Kınık, Nazmi Mutlu Karakaş, Design: Sibel Tulgar Kınık, Nazmi Mutlu Karakaş, Data Collection and Processing: Nazmi Mutlu Karakaş, Beril Özdemir, Analysis and Interpretation: Ayşegül Haberal, M. Ağah Tekindal, Literature Research: Nazmi Mutlu Karakaş, Writing: Nazmi Mutlu Karakaş.

Financial Disclosure: Supported by the Başkent University Research Fund.

\section{References}

1. Klein AH, Meltzer S, Kenny FM. Improved prognosis in congenital hypothyroidism treated before age three months. J Pediatr 1972;81:912-915.

2. Dussault JH, Coulombe P, Laberge C, Letarte J, Guyda H, Khoury K. Preliminary report on a mass screening program for neonatal hypothyroidism. J Pediatr 1975;86:670-674.
3. Gogakos AI, Duncan Basset JH, Williams GR. Thyroid and bone. Arch Biochem Biophys 2010;503:129-136. Epub 2010 Jun 23

4. Leger J, Ruiz JC, Guibourdenche J, Kindermans C, Garabedian M, Czernichow P. Bone mineral density and metabolism in children with congenital hypothyroidism after prolonged L-thyroxine therapy. Acta Pediatr 1997;86:704-710

5. Stall GM, Harris S, Sokoll LJ, Dawson-Hugues B. Accelerated bone loss in hypothyroid patients overtreated with L-thyroxine. Ann Intern Med 1990;113:265-269.

6. Diamond T, Nery L, Hales I. A therapeutic dilemma: suppresive doses of thyroxine significiantly reduce bone mineral measurements in both premenopausal and postmenopausal women with thyroid carcinoma. J Clin Endocrinol Metab 1991;72:1184-1188.

7. Franklyn JA, Betteridge J, Daykin J, Holder R, Oates GD, Parle JV, Lilley J, Heath DA, Sheppard MC. Long-term thyroxine treatment and bone mineral density. Lancet 1992;340:9-13.

8. Marcocci C, Golia F, Bruno-Bossio G, Vignali E, Pinchera A. Carefully monitored levothyroxine suppressive therapy in not associated with bone loss in premenopausal women. J Clin Endocrinol Metab 1994;78:818-823

9. Misra M, Pacaud D, Petryk A, Collett-Solberg PF, Kappy M, Kappy M; Drug and Therapeutics Committee of the Lawson Wilkins Pediatric Endocrine Society. Vitamin D deficiency in children and its management: review of current knowledge and recommendations. Pediatrics 2008;122:398-417.

10. Jürimae $\mathrm{J}$. Interpretion and application of bone turnover markers in children and adolescents. Curr Opin Pediatr 2010;22:494-500.

11. Civitelli R, Armanento-Villareal R, Napoli N. Bone turnover markers: understanding their value in clinical trails and clinical practice. Osteoporos Int 2009;20:843-851. Epub 2009 Feb 4

12. Bassett JH, Williams GR. Critical role of the hypothalamic-pituitarythyroid axis in bone. Bone 2008;43:41 8-426. Epub 2008 May 16

13. Papadimitriou A, Papadimitriou DT, Papadopoulou A, Nicolaidou P, Fretzayas A. Low TSH levels are not associated with osteoporosis in childhood. Eur J Endocrinol 2007;157;221-223.

14. Engler H, Oettli RE, Riesen WF. Biochemical markers of bone turnover in patients with tyhroid dysfunctions and in euthyroid controls: a crosssectional study. Clin Chim Acta 1999;289;159-172.

15. Chen CJ, ChaoTY, Janckila AJ, Cheng SN, Ku CH, Chu DM. Evaluation of the activity of tartrate-resistant acid phosphatase isoform $5 \mathrm{~b}$ in normal Chinese children-a novel marker for bone growth. J Pediatr Endocrinol Metab 2005;1 8:55-62.

16. Rauchenzauner M, Schmid A, Heinz-Erian P, Kapelari K, Falkensammer G, Griesmacher A, Finkenstedt G, Högler W. Sex-and Age-spesific reference curves for serum markers of bone turnover in healthy children from 2 months to 18 years. J Pediatr Endocrinol Metab 2007;92:443-449. Epub 2006 Nov 14

17. Fischer DC, Mischek A, Wolf S, Rahn A, Salweski B, Kundt G, Haffner D. Paediatric reference values for the C-terminal of fibroblast-growth factor-23, sclerostin, bone-spesific alkaline phosphatase and isoform $5 \mathrm{~b}$ of tartrate-resistant acid phosphatase. Ann Clin Biochem 2012;49:546553. Epub 2012 Sep 14 